\title{
High sedentary behavior and compromised physical capabilities in adult smokers despite the suitable level of physical activity in daily life
}

\section{Comportamento sedentário alto e comprometimento da aptidão física em tabagistas adultos apesar do nível adequado de atividade física na vida diária}

\author{
Vinicius Tonon Lauria ${ }^{\top}$ \\ Evandro Fornias Sperandio ${ }^{1}$ \\ Agatha Caveda Matheus ${ }^{1}$ \\ Rodrigo Pereira da Silva ${ }^{\top}$ \\ Marcello Romiti² \\ Antônio Ricardo de Toledo Gagliardi² \\ Rodolfo Leite Arantes ${ }^{2}$ \\ Victor Zuniga Dourado
}

\begin{abstract}
Sedentary behavior may play an important role for health outcomes, regardless of the amount of physical activity in daily life (PADL).We aimed to evaluate and compare sedentary behavior as well as physical capabilities in physically active smokers and non-smokers. Twenty-eight adult smokers and 38 non-smokers free of lung disease were matched for age, sex, body mass index, body composition, cardiovascular risk and moderate-to-vigorous PADL.Participants underwent spirometry, cardiopulmonary exercise test (CPET), six-minute walk test (6MWT), isokinetic dynamometry, and body composition (bioelectrical impedance).Despite the similar amount of moderate-to-vigorous PADL (median, 4.5h/week for smokers and 4.0h/week for non-smokers), smokers spent more time lying (median, $8.2 \mathrm{~h} /$ week: $95 \%$ confidence interval, 5.4 to $19.1 \mathrm{vs.} 6.1 \mathrm{~h} /$ week: 3.7 to 11.2 ) and in sedentary activities (median, 100h/week: 66 to 129 vs. $78 \mathrm{~h} /$ week: 55 to 122) compared to non-smokers. Smokers also presented worse spirometry, peak V'O2 and maximum heart rate in the CPET, 6MWT, and isokinetic indices $(\mathrm{p}<0.05)$. We observed a strong correlation between the time spent lying and spirometry $(r=-0.730)$ in smokers. Smoking is related to higher sedentary behavior, despite the suitable PADL. An appropriate PADL did not reduce the deleterious effects of smoking on physical capabilities. Interrupting sedentary behavior may be an appropriate intervention target in smokers for reducing the risk of diseases.
\end{abstract}

Key words: Physical Fitness; Sedentary Lifestyle; Smoking.

Resumo - O comportamento sedentário pode desempenhar papel importante nos resultados relacionados à saúde, independentemente da quantidade de atividade física na vida diária (AFVD). Nosso objetivo foi avaliar e comparar o comportamento sedentário, bem como a capacidade funcional em tabagistas e não tabagistas fisicamente ativos. Vinte e oito tabagistas adultos e 38 não tabagistas sem doenças respiratórias foram pareados por idade, sexo, indice de massa corporal, composição corporal, risco cardiovascular e AFVD moderada a intensa. Os participantes realizaram espirometria, teste de exercicio cardiopulmonar (TECP), teste de caminhada de seis minutos (TC6), dinamometria isocinética e composição corporal (bioimpedância). Apesar da quantidade semelhante de AFVD moderada a intensa (mediana, 4,5 h/semana para tabagistas e 4,0h/semana para os não tabagistas), os tabagistas passaram mais tempo deitados (mediana, 8,2 h/semana: intervalo de confiança de 95\%, 5,4 a 19,1 vs. 6,1 h/semana: 3,7 a 11,2) e em atividades sedentárias (mediana, 100h/semana: 66 a 129 vs. 78h/semana: 55 a 122) em comparação com não tabagistas. Os tabagistas também apresentaram pior espirometria, pico de $V$ 'O2 e freqüência cardíaca máxima no TECP, TC6 e indices isocinéticos ( $p<0,05)$. Observamos uma forte correlação entre o tempo gasto deitado e a espirometria $(r=-0,730)$ nos tabagistas. O tabagismo está relacionado ao maior comportamento sedentário, apesar do nivel AFVD adequado. Um nivel AFVD adequado não reduziu os efeitos deletérios do tabagismo na capacidade funcional. Interromper o comportamento sedentário pode ser uma intervenção apropriada em tabagistas para a prevenção de doenças.

Palavras-chave: Aptidão Física; Estilo de Vida Sedentário; Hábito de Fumar.
1 Federal University of São Paulo. Laboratory of Epidemiology and Human Movement. Santos, SP. Brazil.

2 Angiocorpore Institute of Cardiovascular Medicine. Santos, SP. Brazil.

Received: 19July 2016 Accepted: 15 February 2017 


\section{INTRODUCTION}

Sedentary behaviors are linked to health problems ${ }^{1}$. It can be evaluated through self-report or it can be directly measured using activity monitors. During the last decade, several studies conducted evaluations of selfreported sedentary behavior ${ }^{2}$, but those evaluations have presented spurious associations with results obtained through accelerometers ${ }^{3}$.

Smokers commonly have reduced physical capabilities compared to their nonsmoking counterparts ${ }^{4}$. The reduction of physical capabilities and its association with the level of physical activity in daily life (PADL) have been increasingly discussed in the literature ${ }^{5}$. It has been suggested by epidemiological studies that adequate levels of PADL are associated with lower pulmonary function decline and lower incidence of chronic obstructive pulmonary disease (COPD) in smokers ${ }^{6}$. It is rational to state that smokers with a suitable PADL might present preserved lung function. However, the evaluation method employed for assessing PADL may be a confounding factor in this context. For this reason, the use of triaxial accelerometers has been prioritized in epidemiological studies in recent years for assessing sedentary behavior ${ }^{2}$. Smoking affects cardiorespiratory fitness, however, whether this negative impact occurs in smokers with appropriate PADL needs further clarification.

Although scientific evidence is growing about the impact of sedentary behavior in increased risk of mortality from all causes, regardless of physical activity $^{7}$, whether sedentary behavior is higher in physically active adult smokers has not yet been sufficiently investigated, especially using triaxial accelerometers. The higher sedentary behavior could explain partially the increased risk of smoking for developing chronic diseases and preventive strategies should be investigated.

Our hypothesis is that sedentary behavior is high and physical capabilities are compromised in smokers without airflow obstruction, despite the suitable PADL assessed directly through triaxial accelerometry. Accordingly, the aim of this study was to evaluate and compare the sedentary behavior and physical capabilities in physically active adults, smokers, and nonsmokers.

\section{METHODOLOGIAL PROCEDURES}

We conducted a cross-sectional study with a convenience sample. Sixtysix physically active adults, 28 smokers free from lung diseases and 38 nonsmokers, were selected from the EPIMOV Study (Epidemiology and Human Movement Study). Participants were carefully matched for age, sex, body mass index (BMI), body composition, cardiovascular risk and PADL. Only volunteers who have reached the minimum recommendations of at least $150 \mathrm{~min} /$ week of moderate-to-vigorous physical activity, 
measured by accelerometer, were included. Participants with obstructive lung disease and COPD diagnosis were also excluded.

The evaluations were performed in two subsequent days, 7 days apart. On the first day, participants underwent clinical evaluation, spirometry, cardiopulmonary exercise testing (CPET) and were instructed how to use the triaxial accelerometer. On the second day, they returned the accelerometer and underwent the assessment of body composition, postural balance, isokinetic muscle function and six-minute walk test (6MWT).

All participants signed a free and informed consent. The Ethics Committee on Human Research of the Federal University of São Paulo (UNIFESP) approved the present study (933.167).

\section{Clinical assessment}

Initially, the participants answered the physical activity readiness questionnaire (PAR-Q) Cardiovascular risk stratification was performed according to the recommendations of the American College of Sports Medicine ${ }^{8}$. Smoking was investigated by self-report and was considered smokers subjects who reported current smoking and have smoked 100 or more cigarettes during their lifetime ${ }^{9}$. The smoking load was calculated in pack-years. At the end of the clinical assessment, body weight and height were measured and BMI was calculated.

\section{Spirometry}

The maneuver of forced vital capacity (FVC) was performed using a calibrated spirometer (Quark PFT; COSMED, Pavonadi Albano, Italy) according to the criteria established by the American Thoracic Society ${ }^{10}$. Forced expiratory volume in one second (FEV1), FVC and FEV1/FVC ratio were measured in absolute and predicted values ${ }^{11}$. The spirometric restrictive pattern was identified in accordance with previous described (i.e., FEV1/FVC $>0.70$ and $\mathrm{FVC}<80 \%$ of pred.) ${ }^{12}$.

\section{Cardiopulmonary exercise testing}

The CPET was performed on a treadmill (ATL, Inbrasport, Curitiba, Brazil) under a ramp protocol, with individualized increases in speed and inclination, according to the estimated maximum oxygen uptake $\left(\mathrm{V}^{\prime} \mathrm{O}_{2 \max }\right)$. Gas exchange and ventilatory variables were analyzed breath by breath, using a computerized gas analyzer periodically calibrated according to the manufacturer's recommendations (Quark PFT; COSMED, Pavona Albano, Italy).

Oxygen uptake, carbon dioxide production (V'CO2), minute ventilation (V'E) and tidal volume (VT) were collected breath by breath. Heart rate (HR) was monitored throughout the test by a 12-lead electrocardiogram (C12x, COSMED, Pavano of Albano, Italy). The anaerobic threshold was evaluated by means of $\mathrm{v}$-slope method.

We also assessed the following submaximal relationships: cardiovascular efficiency $\left(\Delta \mathrm{HR} / \Delta \mathrm{V}^{\prime} \mathrm{O} 2\right)$, ventilatory efficiency $\left(\Delta \mathrm{V}^{\prime} \mathrm{E} / \Delta \mathrm{V}^{\prime} \mathrm{CO} 2\right)$ and ventilatory pattern $\left(\Delta \mathrm{V}^{\prime} \mathrm{T} / \Delta \ln \mathrm{V}^{\prime} \mathrm{E}\right)$. 


\section{Body composition}

Body composition was measured by bioelectrical impedance (BIODYNAMICS, 310E, Detroit, USA) carried out at room temperature. Lean body mass (LBM) and body fat were calculated using a group-specific reference equation for healthy individuals ${ }^{13}$.

\section{Postural balance}

We measured postural balance by evaluating the kinetic behavior of the center of pressure (COP) on a force platform (BIOMEC400, EMGSystem, São Jose dos Campos, Brazil). Participants were instructed to remain as static as possible in the following situations: bipedal support with open eyes; bipedal support with eyes closed; semi-tandem support with eyes open; and semi-tandem support with eyes closed.

\section{Isokinetic muscle assessment}

Peripheral muscle function was evaluated by isokinetic dynamometry (Biodex, System 4, NY). The dominant lower and upper limbswere evaluated. The strength of the flexor and extensor muscles of the knee and elbow joints was evaluated through six repetitions at 60 degrees/s. The muscle endurance was evaluated by thirty repetitions at 300 degrees/s. Peak and average torque, power, and total work were measured in each of the imposed speeds.

\section{Six-minute walk test}

The six-minute walk test (6MWT) was performed according to the standards of the American Thoracic Society ${ }^{14}$. The distance covered on the test was recorded in meters and percentage of predicted values ${ }^{15}$.

\section{Triaxial accelerometry}

The PADL was evaluated with a previously validated triaxial accelerometer (ActiGraph, GT3x+, Pensacola, FL) ${ }^{16}$. Participants used the triaxial accelerometer during 7 days. The minimum level of physical activity in terms of quantity and intensity was established as $150 \mathrm{~min} /$ week of moderate-tovigorous physical activity according to previous recommended ${ }^{17}$.

\section{Statistical analysis}

The sample was calculated using as a reference the minimum clinically significant difference of $442 \mathrm{~mL} / \mathrm{min}$ (i.e., a lower limit of normal) of peak V'O2 during the $\mathrm{CPET}^{18}$. Considering the standard deviation of the peak V'O2 in healthy adults of about $400 \mathrm{~mL} / \mathrm{min}$, we calculated the standardized magnitude of the effect. Stipulating the probability of alpha error at 0.05 and beta error at 0.20 , the sample size was approximately 16 subjects in each group.

Statistical analysis was performed using SPSS version 22.0. Data were initially analyzed descriptively. The normality of the variables was assessed by Kolmogorov-Smirnov test. The data are presented as mean \pm standard deviation or median (interquartile range) according to the symmetrical 
or asymmetrical distribution. Comparisons between proportions were analyzed by $x^{2}$ or Fisher's exact test. Continuous variables were compared using the Student $t$ test. To evaluate the influence of sedentary behavior on lung function in smokers, we evaluated the correlation between the variables of triaxial accelerometry and pulmonary function by means of the Pearson or Spearman correlation coefficients according to the distribution of the data. The probability of alpha error was set at $5 \%$.

\section{RESULTS}

Participants were carefully matched for age, sex, anthropometry, body composition (Table 1), cardiovascular risk and PADL. As expected, smokers had lower values of FEV1 (Table 1). However, no participant presented obstructive lung disease according to the spirometric indices. Eight percent of nonsmokers and $17 \%$ of smokers had a spirometric restrictive pattern $(\mathrm{p}=0.236)$.

Table 1. Demographics, anthropometrics, body composition, and spirometric indices in the 66 individuals studied.

\begin{tabular}{|c|c|c|c|c|c|c|}
\hline & & \multicolumn{2}{|c|}{ Non-smokers $(n=38)$} & \multicolumn{2}{|c|}{ Smokers $(n=28)$} & \multirow[b]{2}{*}{$p$ value } \\
\hline & & Mean & SD & Mean & SD & \\
\hline $\operatorname{Age}(\mathrm{y}$ & & 48 & 9 & 47 & 10 & 0.671 \\
\hline \multirow[t]{2}{*}{ Sex\# } & Females & 27 & $71 \%$ & 20 & $71 \%$ & 1.000 \\
\hline & Males & 11 & $29 \%$ & 8 & $29 \%$ & 1.000 \\
\hline \multicolumn{2}{|c|}{ Hypertension } & 5 & $13.2 \%$ & 4 & $14.3 \%$ & 0.897 \\
\hline \multicolumn{2}{|c|}{ Diabetes } & 5 & $13.2 \%$ & 3 & $10.7 \%$ & 0.758 \\
\hline \multicolumn{2}{|c|}{ Dyslipidemia } & 10 & $26.3 \%$ & 7 & $25 \%$ & 0.905 \\
\hline \multicolumn{2}{|c|}{ Obesity } & 15 & $39.5 \%$ & 8 & $27 \%$ & 0.290 \\
\hline \multicolumn{2}{|c|}{ Body mass index $\left(\mathrm{kg} / \mathrm{m}^{2}\right)$} & 28.6 & 3.8 & 26.9 & 5.2 & 0.129 \\
\hline \multicolumn{2}{|c|}{ Waistcircumference(cm) } & 87 & 9 & 87 & 11 & 1.000 \\
\hline \multicolumn{2}{|c|}{ Hipcircumference(cm) } & 102 & 9 & 102 & 12 & 1.000 \\
\hline \multicolumn{2}{|c|}{ Waist to hip ratio } & 0.86 & 0.10 & 0.86 & 0.07 & 1.000 \\
\hline \multicolumn{2}{|c|}{$\mathrm{FVC}(\mathrm{L})$} & 3.57 & 1.06 & 3.31 & 0.96 & 0.309 \\
\hline \multicolumn{2}{|c|}{ FVC(\% pred.) } & 97 & 14 & 92 & 14 & 0.156 \\
\hline \multicolumn{2}{|c|}{ FEV1(L) } & 2.92 & 0.83 & 2.71 & 0.79 & 0.303 \\
\hline \multicolumn{2}{|c|}{ FEV1(\% pred.) } & 97 & 13 & $91^{*}$ & 13 & 0.068 \\
\hline \multicolumn{2}{|c|}{ FEV1/FVC(\%) } & 82 & 5 & 82 & 5 & 1.000 \\
\hline \multicolumn{2}{|c|}{ FEV1/FVC(\% pred.) } & 101 & 6 & 100 & 5 & 0.476 \\
\hline \multicolumn{2}{|c|}{ Smoking load(pack-years) } & - & - & 18 & 17 & - \\
\hline \multicolumn{2}{|c|}{ Lean body mass(kg) } & 50.5 & 10.5 & 49.4 & 10.0 & 0.669 \\
\hline \multicolumn{2}{|c|}{ Lean body mass(\% of total) } & 67 & 6 & 69 & 8 & 0.249 \\
\hline \multicolumn{2}{|c|}{ Fat body mass(kg) } & 23.8 & 6.0 & 23.0 & 10.4 & 0.694 \\
\hline \multicolumn{2}{|c|}{ Fat body mass ( $\%$ of total) } & 32 & 6 & 30 & 8 & 0.249 \\
\hline
\end{tabular}

${ }^{*} p<0.05$ : non-smokers vs. smokers; \#Presented as count and\%; FVC = forced vital capacity; FEV1 $=$ forced expiratory volume in the first second.

Participants were also closely matched in the number of weekly hours spent in the moderate-to-vigorous physical activity. Respectively, smokers and nonsmokers showed similar time spent per week in moderate (median, 
$4.5 \mathrm{~h}$ : interquartile range, 3.6 to 6.2 vs. $4.0 \mathrm{~h}$ : 3.5 to 5.3$)$ and vigorous physical activity ( $0.06 \mathrm{~h}$ : 0.03 to $0.16 \mathrm{~h}$ vs. $0.07: 0.04$ to 0.16$)$. There were no significant differences also in relation to the weekly energy expenditure and the average number of steps taken daily. Despite this, we observed that the smokers spent significantly $(\mathrm{p}<0.05)$ more hours per week in sedentary physical activities(100 h: 66 to 129 vs. 78 h: 55 to 122$)$ and in supine position (8.2 h: 5.4 to 19.1 vs. 6.1 h: 3.7 to 11.2 )compared to nonsmokers. We observed in smokers, a strong negative correlation between the weekly time spent lying and the FEV1/FVC ratio $(r=-0.730, p<0.001)$.

Table 2. Physiological responses to the cardiopulmonary exercise testing in the 66 individuals studied.

\begin{tabular}{|c|c|c|c|c|c|}
\hline & \multicolumn{2}{|c|}{ Non-smokers } & \multicolumn{2}{|c|}{ Smokers } & \multirow[b]{2}{*}{$p$ value } \\
\hline & Mean & SD & Mean & SD & \\
\hline \multicolumn{6}{|l|}{ Metabolic responses } \\
\hline Peak V'O ${ }_{2}(\mathrm{~mL} / \mathrm{min})$ & 2159 & 790 & 1950 & 773 & 0.039 \\
\hline Peak V'O $\mathrm{O}_{2}(\mathrm{~mL} / \mathrm{min} / \mathrm{kg})$ & 28.4 & 8.7 & 27.0 & 9.1 & 0.528 \\
\hline Peak V'O ${ }_{2}(\%$ pred.) & 102 & 16 & $92^{\star}$ & 14 & 0.010 \\
\hline Peak V'O ${ }_{2}(\mathrm{MET})$ & 7.9 & 2.4 & 7.7 & 2.2 & 0.730 \\
\hline Anaerobic threshold(mL/min) & 1396 & 498 & 1332 & 554 & 0.624 \\
\hline Anaerobic threshold(\% maximum) & 65 & 7 & 68 & 9 & 0.132 \\
\hline $\mathrm{V}^{\prime} \mathrm{CO}_{2} / \mathrm{V}^{\prime} \mathrm{O}_{2}$ maximum & 1.20 & 0.12 & 1.21 & 0.11 & 0.730 \\
\hline \multicolumn{6}{|l|}{ Cardiovascular responses } \\
\hline HR maximum (bpm) & 162 & 14 & $152^{*}$ & 20 & 0.019 \\
\hline HR maximum(\% pred.) & 94 & 6 & $88^{\star}$ & 9 & 0.001 \\
\hline HR recovery in $1 \mathrm{~min}(\mathrm{bpm})$ & 25 & 6 & 25 & 6 & 1.000 \\
\hline V'02/HR maximum(mL/min/kg/bpm) & 13.1 & 4.5 & 12.0 & 4.1 & 0.312 \\
\hline \multicolumn{6}{|l|}{ Ventilatory responses } \\
\hline V'E maximum(L/min) & 68.7 & 24.6 & 60.6 & 25.7 & 0.199 \\
\hline V'Tmaximum(L) & 1.87 & 0.62 & 1.63 & 0.60 & 0.121 \\
\hline f maximum(ipm) & 36.8 & 6.4 & 37.2 & 5.8 & 0.794 \\
\hline V'T/CI maximum & 0.63 & 0.15 & 0.59 & 0.13 & 0.262 \\
\hline \multicolumn{6}{|l|}{ Submaximal relationships } \\
\hline$\Delta \mathrm{V}^{\prime} \mathrm{E} / \Delta \mathrm{V}^{\prime} \mathrm{CO}_{2}(\mathrm{~L} / \mathrm{min} / \mathrm{L} / \mathrm{min})$ & 25.8 & 3.2 & 27.2 & 3.2 & 0.083 \\
\hline$\Delta \mathrm{HR} / \Delta \mathrm{V}^{\prime} \mathrm{O}_{2}(\mathrm{bpm} / \mathrm{L} / \mathrm{min})$ & 49.1 & 16.7 & 48.6 & 13.8 & 0.877 \\
\hline$\Delta V^{\prime} T / \Delta \operatorname{lnV} V^{\prime}$ & 0.74 & 0.22 & 0.67 & 0.35 & 0.323 \\
\hline
\end{tabular}

${ }^{*} p<0.05$ : non-smokers vs. smokers; $V$ '02 = oxygen uptake; V'CO2 = carbon dioxide production; $\mathrm{HR}=$ heart rate; $V$ ' $E$ = minute ventilation; $V^{\prime} T$ = tidal volume; $f=$ respiratory rate; $I C=$ inspiratory capacity.

Smokers presented worse cardiorespiratory fitness. The peak V'O2 and maximum HR obtained in the CPET were significantly lower in smokers (Tables 2 and 3). We did not observe other significant differences in ventilatory, cardiovascular, metabolic and submaximal responses to the CPET (Table 2). Smokers also had lower maximum HR at the end of the $6 \mathrm{MWT}$ as well as lower six-minute walk distance (Table 3). There was a significant negative correlation between smoking load and peak $\mathrm{V}^{\prime} \mathrm{O} 2 / \mathrm{kg}$ $(\mathrm{r}=-0.44 ; \mathrm{p}<0.001)$. 
Table 3. Physiological responses to the six-minute walk test in the 66 individuals studied.

\begin{tabular}{lccccc}
\hline & \multicolumn{3}{c}{ Non-smokers } & \multicolumn{2}{c}{ Smokers } \\
\hline & Mean & SD & Mean & SD & p value \\
\hline Heart rate initial(bpm) & 77 & 13 & 73 & 12 & 0.206 \\
Heart rate final(bpm) & 115 & 20 & $102^{*}$ & 24 & 0.019 \\
Heart rate initial(\% pred.) & 45 & 8 & 43 & 7 & 0.294 \\
Heart rate final(\% pred.) & 66 & 11 & $59^{*}$ & 12 & 0.016 \\
Dyspnea initial\# & 0.16 & 0.48 & 0.66 & 1.25 & 0.027 \\
Dyspnea final\# & 2.34 & 1.98 & 2.60 & 1.97 & 0.599 \\
Leg fatigue initial\# & 0.32 & 0.83 & 0.40 & 0.91 & 0.711 \\
Leg fatigue final\# & 2.75 & 2.06 & 2.40 & 1.75 & 0.470 \\
6-min walk distance(m) & 590 & 81 & 554 & 102 & 0.115 \\
6-min walk distance(\% pred.) & 106 & 12 & $99^{*}$ & 14 & 0.037 \\
\hline
\end{tabular}

${ }^{*} p<0.05$ : non-smokers vs. smokers \#Borg scale CR10

We observed significantly lower values of isokinetic muscle strength of the lower and upper limbs in smokers (Table 4). Only knee flexors presented a significant reduction in muscle function in smokers. For the upper body, the total work for elbow flexion at 60 degrees/s and peak torque for elbow extension at 300 degrees/s were significantly lower in smokers.

Table 4. Muscle function evaluated by means of isokinetic dynamometer in 38 nonsmokers and 28 smokers participants.

\begin{tabular}{|c|c|c|c|c|c|}
\hline & \multicolumn{2}{|c|}{ Non-smokers } & \multicolumn{2}{|c|}{ Smokers } & \multirow[b]{2}{*}{$p$ value } \\
\hline & Mean & SD & Mean & SD & \\
\hline \multicolumn{6}{|l|}{ Knee extension at $60^{\circ} / \mathrm{s}$} \\
\hline Peak torque(Nm) & 124 & 49 & 116 & 61 & 0.556 \\
\hline Total work(kJ) & 498 & 257 & 450 & 259 & 0.457 \\
\hline Average power(Watts) & 66 & 32 & 66 & 37 & 1.000 \\
\hline Average peak torque(Nm) & 104 & 47 & 104 & 57 & 1.000 \\
\hline \multicolumn{6}{|l|}{ Knee flexion at $60^{\circ} / \mathrm{s}$} \\
\hline Peak torque(Nm) & 60 & 26 & $47^{*}$ & 31 & 0.049 \\
\hline Total work(kJ) & 273 & 153 & $200^{*}$ & 156 & 0.042 \\
\hline Average power(Watts) & 33 & 19 & 28 & 21 & 0.316 \\
\hline Average peak torque(Nm) & 52 & 25 & 42 & 29 & 0.138 \\
\hline \multicolumn{6}{|l|}{ Knee extension at $300 \%$} \\
\hline Peak torque(Nm) & 62 & 25 & 59 & 29 & 0.654 \\
\hline Total work(kJ) & 1466 & 690 & 1227 & 671 & 0.164 \\
\hline Average power(Watts) & 117 & 59 & 102 & 57 & 0.304 \\
\hline Average peak torque(Nm) & 50 & 21 & 47 & 22 & 0.576 \\
\hline \multicolumn{6}{|l|}{ Knee flexion at $300 \% \mathrm{~s}$} \\
\hline Peak torque(Nm) & 55 & 21 & 47 & 20 & 0.123 \\
\hline Total work(kJ) & 825 & 516 & $548^{*}$ & 470 & 0.028 \\
\hline Average power(Watts) & 57 & 39 & 41 & 36 & 0.093 \\
\hline Average peak torque(Nm) & 45 & 19 & 37 & 17 & 0.082 \\
\hline \multicolumn{6}{|l|}{ Elbow extension at $60 \%$} \\
\hline Peak torque(Nm) & 38 & 18 & 32 & 18 & 0.185 \\
\hline Total work(kJ) & 226 & 113 & $169^{*}$ & 132 & 0.063 \\
\hline Average power(Watts) & 25 & 14 & 20 & 16 & 0.181 \\
\hline Average peak torque(Nm) & 34 & 16 & 28 & 18 & 0.158 \\
\hline
\end{tabular}

Continue... 


\begin{tabular}{|c|c|c|c|c|c|}
\hline & \multicolumn{2}{|c|}{ Non-smokers } & \multicolumn{2}{|c|}{ Smokers } & \multirow[b]{2}{*}{$\mathrm{p}$ value } \\
\hline & Mean & SD & Mean & SD & \\
\hline \multicolumn{6}{|l|}{ Elbow flexion at $60 \%$ s } \\
\hline Peak torque(Nm) & 32 & 14 & 27 & 13 & 0.144 \\
\hline Total work(kJ) & 203 & 101 & 164 & 102 & 0.056 \\
\hline Average power(Watts) & 22 & 11 & 19 & 11 & 0.277 \\
\hline Average peak torque(Nm) & 30 & 14 & 25 & 13 & 0.144 \\
\hline \multicolumn{6}{|l|}{ Elbow extension at $300 \% \mathrm{~s}$} \\
\hline Peak torque(Nm) & 35 & 12 & 32 & 13 & 0.336 \\
\hline Total work(kJ) & 737 & 508 & 547 & 485 & 0.130 \\
\hline Average power(Watts) & 45 & 39 & 34 & 35 & 0.241 \\
\hline Average peak torque(Nm) & 28 & 10 & 25 & 11 & 0.252 \\
\hline \multicolumn{6}{|l|}{ Elbow flexion at $300 \%$ s } \\
\hline Peak torque(Nm) & 30 & 9 & $25^{\star}$ & 9 & 0.029 \\
\hline Total work(kJ) & 720 & 310 & 590 & 306 & 0.095 \\
\hline Average power(Watts) & 36 & 24 & 27 & 22 & 0.123 \\
\hline Average peak torque(Nm) & 23 & 7 & 20 & 8 & 0.110 \\
\hline
\end{tabular}

${ }^{*} p<0.05$ : non-smokers vs. smokers

We observed worse postural balance in smokers considering the anteroposterior median amplitude in bipedal support with eyes closed, but it was not statistically significant $(1.53 \mathrm{~cm} /$ height-m: 1.23 to 2.01 vs. 1.36 $\mathrm{cm} /$ height-m: 0.98 to $1.68 ; \mathrm{p}=0.08$ ).

\section{DISCUSSION}

We compared physical capabilities between nonsmokers and smokers without airflow obstruction who attend the minimal recommendations of physical activity. We observed that, even maintaining an appropriate PADL, smokers present differences in relation to nonsmokers regarding physical capabilities domains. Moreover, we observed an association between smoking and higher amounts of sedentary behavior, regardless of the suitable PADL.

Interestingly, the smokers in the present study, even reaching the minimum recommendations of at least $150 \mathrm{~min} /$ week of moderate-tovigorous physical activity, showed higher amounts of sedentary physical activities and time spent lying compared to non-smokers. In the group of smokers, the correlation between this sedentary behavior and lung function was consistent. Although the correlation between quantity and intensity of daily physical activity and lung function has been superficially assessed using accelerometers, there are strong evidences that PADL may be an independent risk factor for the decline in lung function and occurrence of COPD over time ${ }^{6}$. Our results reinforce the evidence that physical activity and sedentary behavior are independent attributes. The increase in sedentary behaviors was observed in patients with COPD who, in addition to airflow obstruction, suffer from skeletal muscle dysfunction ${ }^{19}$. However, the information regarding smokers free of COPD is scarce. Previous studies have linked the sedentary behavior and clinical outcomes 
such as cardiovascular disease and mortality ${ }^{20}$. Although few studies have focused exclusively on smoking, there is evidence to support that high amount of sedentary behavior is associated with cardiovascular, cancer, type 2 diabetes incidence and all-cause mortality ${ }^{21}$. Despite the fact that high levels of moderate physical activity (i.e., about 60-75 min per day) can attenuate the risk of death, it doesn't eliminate the risk of mortality related to sedentary behavior ${ }^{22}$. Moreover, both sedentary behavior and physical activity played a similarly important role as prognostic markers of heart failure ${ }^{20}$. Thus, both physical activity and sedentary time may be appropriate intervention targets for preventing this disease.

Our study reinforces the negative impact of smoking, even in people with appropriate PADL. In fact, one large study evaluated the impact of walking time in daily life and showed that, regardless of smoking and other confounders, individuals who spent more time standing on a daily basis had a mortality up to $24 \%$ lower compared to participants with the highest amount of this sedentary behavior ${ }^{23}$. Our results suggest the need for more careful evaluation of the relationship between smoking and sedentary behavior as well as the influence of sedentary behavior on lung function decline and occurrence of COPD over time. We were unable to find other studies that evaluated this association through accelerometers with inclinometer as we have done in the present study.

We observed worse cardiorespiratory fitness in smokers. Peak V'O2 and maximum HR at the end of the CPET were significantly reduced in smokers. Smoking impairs cardiac function during exercise due to reduced $\mathrm{O} 2$ transport capacity ${ }^{24}$. Furthermore, smoking requires additional energy cost, due to increased respiratory muscle work. With the increased metabolic demand of the respiratory muscles, the cardiac output becomes less perfused in peripheral muscles, reducing exercise tolerance ${ }^{25}$. Our results using triaxial accelerometry confirm the negative repercussion of smoking on cardiorespiratory fitness. In the present study, we observed a moderate but significant negative correlation between smoking load and peak V'O2. In fact, there is recent evidence on the dose-response relationship between smoking load and cardiorespiratory fitness. Misigoj-Durakovic et al. ${ }^{4}$ reported a significant reduction in peak V'O2 even in smokers with a smoking load of 5 pack-years.

Muscle strength and endurance were significantly lower in smokers in our study. There is evidence that the muscles of asymptomatic smokers are weaker and less resistant to fatigue than those of nonsmokers ${ }^{26}$. Our results also indicate that skeletal muscle dysfunction in smokers without airflow obstruction is present, even considering a suitable PADL. Although the mechanisms for that is unknown, this could be caused by the increased inflammatory mediators, proteolysis, and inhibition of protein synthesis, which are common findings in smokers ${ }^{26}$. Fortunately, several negative effects of smoking can be reversed after smoking cessation.

In the present study, the postural balance was evaluated, which is also a domain of physical capability. Although it did not reach the established 
significance level, we have observed that the postural balance seems to be reduced in smokers. Interestingly, the association between smoking and poor postural balance has been already reported ${ }^{27}$. A large cohort study assessed the postural balance of smokers aged 20 years and the assessment was repeated at 53 years ${ }^{28}$. The authors reported the significant influence of smoking in time of uni-pedal balance (blindfolded) over the years. The decline in lung function is associated with the decline in general health, and cognitive function, commonly seen in heavy smokers. It is very likely that the decline in cognition associated with smoking is the most important attribute to explain the worst postural balance in smokers ${ }^{29}$. Also, there is evidence that smoking affects the peripheral part of the central nervous system via the adverse effects of oxidative stress ${ }^{30}$. Despite these findings, is not known if it has a causality relation and the mechanisms to explain the association between smoking and postural balance impairment.

Our study has limitations that should be considered. The convenience sample is not the best way to recruit participants, but it is the feasible one. Our sample showed higher proportion of women in comparison to men. However, our participants were closely matched for the main confounders, including sex. Moreover, we matched the groups regarding the level of PADL using an objective measure (i.e., accelerometry). Interestingly, smokers present low levels of physical capabilities when compared with nonsmokers, even with similar amount of moderate-to-vigorous physical activity.

\section{CONCLUSION}

We can conclude that smokers have worse physical capabilities in comparison with nonsmokers, even in the absence of airflow obstruction and symptoms. In addition, smokers present higher amount of sedentary behavior than nonsmokers, despite the suitable PADL. Thus, interrupting sedentary behavior may be an appropriate intervention target in smokers for preventing diseases. Future studies should investigate the longitudinal association between sedentary behavior and the occurrence of chronic respiratory diseases.

\section{Acknowledgments}

This study received nancial support in the form of a research grant from the São Paulo Research Foundation (FAPESP), in the state of São Paulo, Brazil, grant no. 2011/07282-6

\section{REFERENCES}

1. Hamilton MT, Hamilton DG, Zderic TW. Role of low energy expenditure and sitting in obesity, metabolic syndrome, type 2 diabetes, and cardiovascular disease. Diabetes 2007; 56 (11): 2655-67.

2. Lee I-M, Blair S, MaNSON J, Paffenbaerger Jr. RS. Epidemiologic methods in physical activity studies. Lee I-M, editor. New York: Oxford University Press; 2009.

3. Steele BG, Belza B, Cain K, Warms C, Coppersmith J, Howard J. Bodies in motion: monitoring daily activity and exercise with motion sensors in people with chronic pulmonary disease. J Rehabil Res Dev 2003; 5 (Suppl 2): 45-58. 
4. Misigoj-Durakovic M, Bok D, Soric M, Dizdar D, Durakovic Z, Jukic I. The effect of cigarette smoking history on muscular and cardiorespiratory endurance. J Addict Dis. 2012;31(4):389-96.

5. Furlanetto KC, Mantoani LC, Bisca G, Morita AA, Zabatiero J, Proenca M, et al. Reduction of physical activity in daily life and its determinants in smokers without airflow obstruction. Respirology 2014; 19 (3): 369-75.

6. Garcia-Aymerich J, Lange P, Benet M, Schnohr P, Anto JM. Regular physical activity modifies smoking-related lung function decline and reduces risk of chronic obstructive pulmonary disease: a population-based cohort study. Am J Respir Crit Care Med 2007; 175 (5): 458-63.

7. Schmid D, Ricci C, Leitzmann MF. Associations of objectively assessed physical activity and sedentary time with all-cause mortality in US adults: the NHANES study. PloS one 2015; 10 (3): e0119591.

8. Cabral LTB, Valesin Filho ES, Ueno FH, Yonezaki AM, Rodrigues LMR. Avaliação da qualidade de vida em pacientes com escoliose idiopática do adolescente após tratamento cirúrgico pelo questionário SF-36. Coluna/Columna 2009; 8(3): 315-22.

9. Santos JD, Silveira DV, Oliveira DF, Caiaffa WT. Instruments used to evaluate smoking habits: a systematic review. Cienc Saude Colet 2011; 16 (12): 4707-20.

10. Standardization of Spirometry, 1994 Update. American Thoracic Society. Am J Respir Crit Care Med 1995; 152 (3): 1107-36.

11. Pereira CA, Sato T, Rodrigues SC. New reference values for forced spirometry in white adults in Brazil. J Bras Pneumol 2007; 33 (4): 397-406.

12. Pereira C, Neder J. Diretrizes para testes de função pulmonar. J Bras Pneumol 2002; 28 (Supl 3): s1-s238.

13. Kyle UG, Genton L, Karsegard L, Slosman DO, Pichard C. Single prediction equation for bioelectrical impedance analysis in adults aged 20--94 years. Nutrition 2001; 17 (3): 248-53.

14. Pereira CAC. Diretrizes para testes de função pulmonar. J Pneumol. 2002;28(Suppl 3):1-82.

15. Dourado VZ, Vidotto MC, Guerra RL. Reference equations for the performance of healthy adults on field walking tests. J Bras Pneumol 2011; 37 (5): 607-14.

16. Troiano RP, Berrigan D, Dodd KW, Masse LC, Tilert T, McDowell M. Physical activity in the United States measured by accelerometer. Med Sci Sports Exerc 2008; 40 (1): 181-8.

17. American College of Sports Medicine Position Stand. The recommended quantity and quality of exercise for developing and maintaining cardiorespiratory and muscular fitness, and flexibility in healthy adults. Medicine and science in sports and exercise 1998; 30 (6): 975-91.

18. Neder JA, Nery LE, Castelo A, Andreoni S, Lerario MC, Sachs A, et al. Prediction of metabolic and cardiopulmonary responses to maximum cycle ergometry: a randomised study. Eur Respir J 1999; 14 (6): 1304-13.

19. Maltais F, Decramer M, Casaburi R, Barreiro E, Burelle Y, Debigare R, et al. An official American Thoracic Society/European Respiratory Society statement: update on limb muscle dysfunction in chronic obstructive pulmonary disease. Am J Respir Crit Care Med 2014; 189 (9): e15-62.

20. Young DR, Reynolds K, Sidell M, Brar S, Ghai NR, Sternfeld B, et al. Effects of physical activity and sedentary time on the risk of heart failure. Circ Heart Fail 2014; 7 (1): 21-7.

21. Biswas A, Oh PI, Faulkner GE, Bajaj RR, Silver MA, Mitchell MS, et al. Sedentary time and its association with risk for disease incidence, mortality, and hospitalization in adults: a systematic review and meta-analysis. Ann Intern Med 2015; 162 (2): 123-32.

22. Ekelund U, Steene-Johannessen J, Brown WJ, Fagerland MW, Owen N, Powell $\mathrm{KE}$, et al. Does physical activity attenuate, or even eliminate, the detrimental association of sitting time with mortality? A harmonised meta-analysis of data from more than 1 million men and women. Lancet 2016; 388 (10051): 1302-10. 
23. van der Ploeg HP, Chey T, Ding D, Chau JY, Stamatakis E, Bauman AE. Standing time and all-cause mortality in a large cohort of Australian adults. Prev Med 2014; 69: 187-91.

24. Kobayashi Y, Takeuchi T, Hosoi T, Loeppky JA. Effects of habitual smoking on cardiorespiratory responses to sub-maximal exercise. J Physiol Anthropol Appl Human Sci 2004; 23 (5): 163-9.

25. Aliverti A, Macklem PT. The major limitation to exercise performance in COPD is inadequate energy supply to the respiratory and locomotor muscles. J Appl Physiol 2008; 105 (2): 749-51.

26. Degens H, Gayan-Ramirez G, van Hees HW. Smoking-induced skeletal muscle dysfunction: from evidence to mechanisms. Am J Respir Crit Care Med 2015; 191 (6): 620-5.

27. Saito T, Miyatake N, Nishii K. Relationship between cigarette smoking and one leg with eyes closed balance in Japanese men. Environmental health and preventive medicine 2015; 20 (5): 388-91.

28. Strand BH, Mishra G, Kuh D, Guralnik JM, Patel KV. Smoking history and physical performance in midlife: results from the British 1946 birth cohort. J Gerontol A Biol Sci Med Sci 2011; 66 (1): 142-9.

29. Anstey KJ, von Sanden C, Salim A, O’Kearney R. Smoking as a risk factor for dementia and cognitive decline: a meta-analysis of prospective studies. Am J Epidemiol 2007; 166 (4): 367-78.

30. Letz R, Gerr F. Covariates of human peripheral nerve function: I. Nerve conduction velocity and amplitude. Neurotoxicol Teratol 1994; 16 (1): 95-104.

\section{CORRESPONDING AUTHOR}

ViniciusTononLauria

Rua Silva Jardim 136 - sala 338 , Vila Mathias - Santos/SP, Brazil. CEP: 11030-101

E-mail: viniciuslauria@hotmail.com 